\title{
Efficacy and Safety of Heated humidified high-flow nasal cannula for Preventing Extubation Failure in Neonates: A Systematic Review and Meta-Analysis
}

\author{
Jia Liu \\ First Peoples Hospital of Neijiang \\ Hongyan Qiu \\ First Peoples Hospital of Neijiang \\ Baihua Zheng \\ First Peoples Hospital of Neijiang \\ Lu Jin \\ First Peoples Hospital of Neijiang \\ Jing Chen ( $\sim 983394631 @ q q . c o m$ ) \\ First Peoples Hospital of Neijiang https://orcid.org/0000-0001-9080-6427
}

\section{Research}

Keywords: Heated humidified high-flow nasal cannula, nasal continuous positive airway pressure, neonate, meta-analysis, randomized controlled trials

Posted Date: February 18th, 2021

DOI: https://doi.org/10.21203/rs.3.rs-190689/v1

License: (c) (i) This work is licensed under a Creative Commons Attribution 4.0 International License. Read Full License 


\section{Abstract}

Background: Heated humidified high-flow nasal cannula (HHHFNC) is gaining popularity as a mode of respiratory support. We updated a meta-analysis examining the efficacy and safety of HHHFNC compared with nasal continuous positive airway pressure (NCPAP) for infants.

Methods: Literature searches were conducted using PubMed, Cochrane Library, OVID, Embase, Web of Science, Chinese Biomedical Literature, Weipu Journal, Wanfang, and CNKI databases up to December 2020. Only randomized controlled trials (RCTs) of HHHFNC versus NCPAP in preventing extubation failure for infants were included.

Results: A total of 13 RCTs research literatures involving 2395 infants were included in the Meta-analysis. The meta-analysis showed the following results. (1) In terms of efficacy, there were no significant differences between two groups in the treatment failure rate (RR: $1.00,95 \% \mathrm{Cl}: 0.73$ to $1.36, \mathrm{P}=0.99$ ) and reintubation rate (RR: $0.86,95 \% \mathrm{Cl}: 0.70$ to $1.06, \mathrm{P}=0.16$ ). While in term of safety, HHHFNC had a significant advantage over NCPAP in reducing the incidence rates of nasal trauma (RR: $0.27,95 \% \mathrm{Cl}: 0.13$ to $0.56, \mathrm{P}=0.0005$ ) and frequent hemorrhoid (RR: $0.40,95 \% \mathrm{Cl}: 0.23$ to $0.70, \mathrm{P}=0.001)$.(2) In terms of secondary outcome measures, there were no significant differences between two groups in hospital mortality rate and incidence rates of BPD, ROP, IVH and duration of reaching full enteral feeding $(P>0.05)$. HHHFNC demonstrated lower incidence of NEC (RR: $0.65,95 \% \mathrm{Cl}: 0.43$ to $0.98, P=0.04)$ than NCPAP.

Conclusion:this meta-analysis showed that HHHFNC appears to be similar to NCPAP in efficacy of preventing extubation failure in infants. It is associated with significantly lower odds of nasal trauma, frequent hemorrhoid and NEC.

\section{Background}

Nasal continuous positive airway pressure (NCPAP) is commonly used in the treatment of acute respiratory distress syndrome, respiratory failure and other dangerous and acute diseases [1]. It is also the first non-invasive auxiliary ventilation mode selected after air tube insertion and invasive ventilation treatment [2]. However, it also has some disadvantages, such as the difficulty of maintaining the device on the baby's face, nasal erosion and abdominal distension [3]. Heated humidified high-flow nasal cannula (HHHFNC) is a new type of noninvasive auxiliary ventilation mode, which is recently considered due to its ease of use, better tolerance, improved nutrition, increased maternal-infant bonding, and less iatrogenic injury [4]. At present, there are many comparative studies on the clinical efficacy of HHHFNC and NCPAP in treating ARDS and preventing extubation failure. There are literature reports at home and abroad on clinical trials of HHHFNC in preventing extubation failure of newborns [4,5]. But there is still a lack of evidence to support the effectiveness and safety of its clinical application, and the therapeutic effect is still controversial [6]. The purpose of this study is to provide evidence-based medical support for clinical practice through systematic evaluation and meta-analysis of randomized controlled trial studies on the efficacy of HHHFNC and NCPAP in preventing extubation failure of infants at home and abroad.

\section{Material And Method}

The PRISMA (Preferred Reporting Items for Systematic Reviews and Meta-Analyses) 15 statement were followed for undertaking and reporting this systematic review and meta-analysis.

\section{Data Sources and Searches}

We searched PubMed, Embase, OVID, Web of Science, Cochrane Library, Wan Fang, CNKI, and CBM databases using combinations of the following keywords: "newborn, infant, neonate", "infants, neonates", "preterm infants", "neonatal prematurity", "prematurity, neonatal", "continuous positive airway pressure" and "heated humidified high flow nasal cannula". Google Scholar was also searched to identify potential relevant literature. In addition, the reference lists of included studies and all related review article were checked for additional trials, published or unpublished. The search was limited to randomized controlled trials (RCTs) published in English or Chinese. 


\section{Inclusion and exclusion criteria}

Studies were selected based on the following inclusion criteria. (i) Research content: Randomized controlled trial of HHHFNC and NCPAP measures to prevent newborns from extubation failure; (ii) Research type: prospective randomized controlled trial, regardless of blind method, withdrawal and missed visit. (iii) Subjects: Newborns (including premature infants) and relevant data were extracted. (iv) Intervention: After extubation, newborns were treated with HHHFNC and NCPAP assisted ventilation modes respectively. (v) Outcomes (1) the main outcome measures included efficacy index (rates of treatment failure and reintubation) and safety index (incidence rates of nasal trauma and frequent hemorrhoid). (2) The second outcome measures included in-hospital mortality rate and incidence rates of BPD, NEC, IVH, ROP and the duration of reaching full enteral feedings.

Exclusion criteria were as follows: (1) retrospective studies, cohort studies, single-case reports, animal studies, reviews, metaanalyses, posters, or abstracts; (2) study objective or intervention measures failed to meet the inclusion criteria; (3) duplicate or multiple publication of the same study; (4) studies without usable data.

\section{Data Extraction and Quality Assessment}

The abstracts of retrieved studies were independently reviewed by two authors and full articles were examined when necessary. The data were extracted independently by these two authors and any disagreements were resolved by discussion with at least one more author until a consensus was reached.

The following data was extracted: general information (first author, country of origin, publication date, number of total case, gestational age, birth weight, interventions) and outcomes ( as defined above).

Risk of bias for each study was assessed using the Cochrane Risk of Bias Tool. Bias was assessed as a judgment (high, low, or unclear) for seven domains: random sequence generation, allocation concealment, blinding of participants and personnel, blinding of outcome assessment, incomplete outcome data, selective reporting, and other sources of bias.

\section{Data Synthesis and Analysis}

The data were pooled using Review Manager 5.3 software. Risk ratio (RRs) were calculated for dichotomous variables in each study. Weighted mean difference (WMD) was calculated for continuous variables, and 95\% confidence interval (Cls) were determined for all effect sizes. Heterogeneity of the included studies for was evaluated using Higgins $\mathrm{I}^{2}$. A random-effect model was used when apparent heterogeneity was detected $\left(I^{2} \geq 50 \%, P<0.05\right)$. Otherwise, a fixed effect model was used $\left(I^{2}<\right.$ $50 \%, P \geq 0.05)$. Potential publication bias was judged by Begg's or Egger's tests. Sensitivity analysis was performed to determine the robustness of the combined data. A p-value $<0.05$ was regarded as statistically significant.

\section{Results}

\section{Basic information of the included studies}

The initial literature search identified 559 citations. After removal of duplicates, 316 studies were screened for eligibility. Of these, 224 were excluded based on title and abstract review, leaving 92 full-text articles for full-text evaluation. An additional 79 studies that failed to meet the inclusion criteria were excluded, leaving 13 RCTs $^{[6-18]}$ for inclusion (Fig. 1).

The main characteristics of these studies are summarized in Table 1. Seven studies were written in English and the other six in Chinese. According to the Cochrane Collaboration Risk of Bias Tool, the quality of all RCTs was acceptable as all reported the method of randomization (Fig. 2). Eight RCTs were conducted using computer-generated lists, six used sealed envelopes, and 0 reported blinding of the doctors and participants. No trial showed an unclear bias due to incomplete outcome data or selective outcome reporting. 
The main characteristics of the eligible literatures included in the meta-analysis

\begin{tabular}{|c|c|c|c|c|c|c|c|c|}
\hline study & country & NO & \multicolumn{2}{|c|}{$\begin{array}{l}\text { HHHFNC } \\
\text { GA(weeks)' Birth weight(g) }\end{array}$} & NO & \multicolumn{2}{|l|}{ NCPAP } & outcomes \\
\hline $\begin{array}{l}\text { Liu CQ } \\
2014^{[17]}\end{array}$ & China & 128 & $35.4 \pm 3.5$ & $1550 \pm 482$ & 127 & $35.6 \pm 3.5$ & $1464 \pm 417$ & acdef \\
\hline $\begin{array}{l}\text { Collins } \\
2014^{[9]}\end{array}$ & Australia & 67 & $27.9 \pm 1.95$ & $1123 \pm 317$ & 65 & $27.6 \pm 1.97$ & $1105 \pm 374$ & abcefghj \\
\hline $\begin{array}{l}\text { Yoder } \\
2013^{[10]}\end{array}$ & America & 212 & $33.5 \pm 3.6$ & $2201 \pm 816$ & 220 & $33.2 \pm 3.2$ & $2108 \pm 782$ & abceh \\
\hline $\begin{array}{l}\text { Manley } \\
2013^{[11]}\end{array}$ & Australia & 152 & $27.7 \pm 2.1$ & $1041 \pm 338$ & 151 & $27.5 \pm 1.9$ & $1044 \pm 327$ & abcdeghi \\
\hline $\begin{array}{l}\text { Manley } \\
2019^{[7]}\end{array}$ & Australia & 381 & $36.9 \pm 2.8$ & $2936 \pm 786$ & 373 & $36.9 \pm 3.0$ & $2885 \pm 790$ & abcde \\
\hline $\begin{array}{l}\text { Kadivar } \\
2016^{[12]}\end{array}$ & Iran & 27 & $28 \llbracket 34$ & No mention & 27 & $28 \rrbracket 34$ & No mention & abgi \\
\hline $\begin{array}{l}\operatorname{Jin} B \\
2019^{[13]}\end{array}$ & China & 38 & $30.7 \pm 1.9$ & $1301 \pm 302$ & 37 & $30.4 \pm 1.9$ & $1265 \pm 298$ & adefghij \\
\hline $\begin{array}{l}\text { Kang WQ } \\
2016^{[15]}\end{array}$ & China & 79 & $26 \llbracket 31$ & $1350 \pm 200$ & 82 & $26 \llbracket 31$ & $1400 \pm 300$ & abcefgh \\
\hline $\begin{array}{l}\text { Li K } \\
2014^{[18]}\end{array}$ & China & 28 & $32.6 \pm 1.5$ & $1269 \pm 165$ & 31 & $32.8 \pm 1.7$ & $1273 \pm 157$ & bcdefghij \\
\hline $\begin{array}{l}\text { Chen J } \\
2016^{[16]}\end{array}$ & China & 66 & $30.2 \pm 3.7$ & $861 \pm 124$ & 63 & $30.5 \pm 3.3$ & $878 \pm 136$ & abdefhi \\
\hline $\begin{array}{l}\text { Gao XY } \\
2017^{[14]}\end{array}$ & China & 40 & $39.9 \pm 1.3$ & $3397 \pm 496$ & 38 & $39.4 \pm 1.5$ & $3375 \pm 434$ & adegj \\
\hline $\begin{array}{l}\text { Soonsawad } \\
2017^{[8]}\end{array}$ & Thailand & 24 & $27 \cdot 6(26,30)^{\mathrm{K}}$ & $900(800,1333)^{k}$ & 25 & $28(25,29.5)^{\mathrm{k}}$ & $980(740,1237)^{\mathrm{K}}$ & abdfgh \\
\hline $\begin{array}{l}\text { Armanian } \\
2019^{[6]}\end{array}$ & Iran & 35 & $30.7 \pm 1.8$ & $1282 \pm 184$ & 37 & $29.9 \pm 3$ & $1153 \pm 226$ & abcg \\
\hline
\end{tabular}

\section{The Treatment Failure Rate}


12 articles with a total of 2336 infants reported the relevant data regarding the treatment failure rate. Data pooling revealed no significant difference between groups (RR: $1.00,95 \% \mathrm{Cl}: 0.73$ to $1.36, \mathrm{P}=0.99$; Fig. 3 ).

\section{The Reintubation Rate}

A total of ten studies reported the rate of reintubation (1071 infants in the HHHFNC group and 1074 infants in NCPAP group). There was no statistically significant difference between two groups (RR: $0.86,95 \% \mathrm{Cl}: 0.70$ to 1.06, $\mathrm{P}=0.16$; Fig. 4).

\section{The Incidence Rates of Nasal Trauma}

Data on the incidence rate of nasal trauma were available in eight articles including 1702 infants. The incidence rate of nasal trauma was significantly lower in the HHHFNC group than the NCPAP group (RR: $0.27,95 \% \mathrm{Cl}: 0.13$ to $0.56, P=0.0005 ; \mathrm{Fig} .5$ ).

\section{The Incidence Rates of Frequent Hemorrhoid}

Ten studies reported the incidence rate of frequent hemorrhoid, and data pooling showed that the rate was significantly lower in the HHHFNC group than the NCPAP group (RR: $0.40,95 \% \mathrm{Cl}: 0.23$ to $0.70, \mathrm{P}=0.001$; Fig. 6 ).

\section{Hospital Mortality}

Data on hospital mortality were available in seven articles including 2168 infants. Data pooling revealed no significant difference between groups (RR: $0.70,95 \% \mathrm{Cl}$ : 0.45 to $1.08, \mathrm{P}=0.11$; Fig. 7 ).

\section{The Duration of Reaching Full Enteral Feedings}

Only four trials with 344 infants reported the the duration of reaching full enteral feedings. There was no statistically significant difference between two groups (RR: $-0.91,95 \% \mathrm{Cl}:-2.72$ to $0.90, \mathrm{P}=0.33$; Fig. 8).

\section{Complications}

A total of 8 articles reported the incidence of necrotizing enterocolitis (666 infants in the HHHFNC group and 674 in the NCPAP group). Pooled data revealed a significantly lower incidence in the HHHFNC group (RR: $0.65,95 \%$ Cl: 0.43 to $0.98, P=0.04$; Table 2). There were no statistically differences in the frequencies of other complications (Table 2), such as BPD, IVH, ROP (P $>0.05)$.

Table 2

The pooled outcome of complications

\begin{tabular}{|c|c|c|c|c|c|c|c|c|c|}
\hline & \multirow[t]{2}{*}{ No. of trials } & \multicolumn{2}{|c|}{ HHHFNC } & \multicolumn{2}{|c|}{ NCPAP } & \multirow[t]{2}{*}{$\mathrm{I}^{2}$} & \multirow[t]{2}{*}{ Effect-Model } & \multirow[t]{2}{*}{ outcomes } & \multirow[t]{2}{*}{$P$} \\
\hline & & case & total & case & total & & & & \\
\hline BPD & 7 & 93 & 430 & 103 & 430 & $0 \%$ & Fixed & $0.83[0.71,1.12]$ & 0.32 \\
\hline IVH & 8 & 19 & 662 & 29 & 675 & $0 \%$ & Fixed & $0.67[0.38,1.17]$ & 0.16 \\
\hline NEC & 8 & 32 & 666 & 50 & 674 & $7 \%$ & Fixed & $0.65[0.43,0.98]$ & 0.04 \\
\hline ROP & 5 & 58 & 311 & 53 & 309 & $0 \%$ & Fixed & $1.07[0.80,1.44]$ & 0.64 \\
\hline
\end{tabular}

\section{Publication Bias}

The large sizes of some pooled samples, such as for the Treatment Failure Rate, allowed for the application of Begg test and Egger test for analysis of publication bias. However, no significant bias was found across the studies include in this metaanalysis $\left(P_{\text {Begg test }}=0.537 ; P_{\text {Egger test }}=0.629\right)$ (Fig. 9 and Fig. 10).

\section{Sensitivity Analysis}

Sensitivity analysis indicated our current data were relatively steady and credible (Fig. 11). 


\section{Discussions}

HHHFNC is a new type of noninvasive ventilation mode, which is a new type of neonatal noninvasive respiratory support mode developed on the basis of nasal catheter oxygen therapy ${ }^{[19]}$. HHHFNC can not only provide humidified respiratory gas and increase the concentration of inhaled oxygen, but also prevent airway heat, water loss and mucosal cilia damage, provide a certain positive airway pressure, improve mucosal perfusion and stimulate respiratory center ${ }^{[20]}$. It is increasingly widely used in neonatal clinic.

The Meta-analysis showed that there was no significant difference in treatment failure rate and reintubation rate between the HHHFNC and the NCPAP groups. It is worth noting that Collins ${ }^{[9]}$ found there were 22 cases (33.8\%) in NCPAP group and 15 cases $(22.3 \%)$ in HHHFNC group failed in extubation and needed recanalization. The remaining 9 cases in HHHFNC group were successfully extubated after NCPAP and nasal intermittent positive pressure ventilation (NIMV) treatment, without further intubation treatment. A recent forward-looking research has also questioned the effectiveness of HHHFNC in preventing extubation failure of premature infants. The research shows that HHHFNC group $(n=30)$ and NCPAP group $(n=34)$ have early-stage babies (28-34 weeks of age) who are respectively subjected to HHHFNC and NCPAP to prevent extubation failure. The failure rate of HHHFNC group $(36.7 \%, 11 / 30)$ was significantly higher than that of NCPAP group $(14.7 \%, 5 / 34)$, and the difference was statistically significant $(P=0.043)$. Among the 11 premature infants with extubation failure in HHHFNC group, 5 cases needed to undergo reinsertion therapy, while the remaining 6 cases were successfully extubated after NCPAP therapy and did not need reinsertion therapy ${ }^{[21]}$. Armanian ${ }^{[6]}$ also pointed out that HHHFNC, as the initial noninvasive auxiliary ventilation mode for the treatment of ARDS in early-born children, increased the risk of recanalization compared with NCPAP. It can be seen that HHHFNC is used to prevent premature infants from extubation failure, and if extubation failure occurs, part of the children can be successfully treated by NCPAP. If NCPAP fails, recanalization and mechanical ventilation are often used to maintain treatment. Chen Jia's research on 129 preterm infants with ultra-low birth weight showed the opposite results. The risk of recanalization within 7 days after primary extubation in HHHFNC group was significantly lower than that in NCPAP group. However, there is no systematic meaning $(P>0.05)$ in recanalization between the two groups within 3 days after the first extubation. This suggests that HHHFNC has instability in preventing premature infants from extubation failure, which may be related to the adoption of HHHFNC for treatment, the gap between nasal plug and nasal cavity, and the inability to better control airway pressure. Therefore, it is very important to accurately evaluate the real pressure generated by HHHFNC ${ }^{[22,}$ 23].

While in terms of safety, HHHFNC had a significant advantage over NCPAP in reducing the incidence rates of nasal trauma. The reason is that nasal congestion does not need to be completely closed when HHHFNC is used for treatment, thus avoiding the pressure on the skin around the nose. In addition, compared with the traditional nasal catheter oxygen inhalation method, the heating and humidification oxygen infusion method can also reduce the incidence rate of nasal mucous membrane injury and hemorrhage, and increase the comfort of affected children. The results of this study also show that the incidence of frequent hemorrhoid in premature infants in HHHFNC group is lower than that in NCPAP group, and the difference has a systematic meaning. This may be related to the fact that the positive airway pressure produced by HHHFNC therapy is lower than that of NCPAP, and the application phase is relatively warm. A retrospective study conducted by GARG in India included 136 very low birth weight premature infants with gestational age $\leq 32$ weeks and birth weight $\leq 1500 \mathrm{~g}$, and the results of analysis also support the above conclusion. In terms of secondary outcomes measurements, there were no significant differences between two groups in the in-hospital mortality rate and incidence rates of BPD, IVH, ROP, and the duration of teaching full enteral feedings ${ }^{[24]}$. This suggests that HHHFNC does not increase or decrease the risk of premature infants' extubation failure compared with NCPAP. Note that the incidence rate of NEC in infants was significantly lower in the HHHFNC group than NCPAP group (RR: $0.65,95 \% \mathrm{Cl}: 0.43$ to $0.98, \mathrm{P}=0.04$ ). This may be related to the treatment of abdominal distension indirectly caused by NCPAP measures, while HHHFNC measures are applied with opposite temperature sum, which produces relatively low abdominal pressure. Considering the safety outcome index, HHHFNC has more advantages than NCPAP in preventing infants from extubation failure. 
However, some limitations of this study should be acknowledged. First, the number of research documents included is relatively small, and there are no documents in other languages except Chinese and English, which are representative and have to be verified. Second, there are differences in the basic conditions of the population included in the study, such as fetal age, birth weight, basic diseases, etc. Third, the level of medical treatment and health care in different regions is different, the types and parameter settings of HHHFNC and NCPAP treatment equipment are different, and the main outcome evaluation index and complication occurrence judgment standard are different, which can affect the evidence strength of the conclusion.

\section{Conclusions}

In conclusion, this meta-analysis showed that HHHFNC appears to be similar to NCPAP in efficacy of preventing extubation failure in infants. It is associated with significantly lower odds of nasal trauma, frequent hemorrhoid and NEC. However, for infants born earlier than 30 weeks of age, whether HHHFNC can be the preferred noninvasive auxiliary ventilation mode recommended clinically still needs further research and confirmation.

\section{Abbrebiations}

HHHFNC:Heated humidified high-flow nasal cannula; NCPAP:nasal continuous positive airway pressure; RCT: randomized controlled trial; ARDS: acute respiratory distress syndrome; RR: Risk ratio; WMD: Weighted mean difference; Cl: confidence interval

\section{Declarations}

\section{Acknowledgement}

Not applicable.

\section{Authors' contributions}

$\mathrm{JH}$ and $\mathrm{JC}$ contributed to the study designn, data collection, interpretation of data, and drafting the report. HQ, BZ and LJ contributed to the data collection and statistical analysis and reviewed the report. All authors read and approved the final manuscript.

\section{Funding}

This study is funded by Neijiang Science and Technology Incubating Project (CN) (No. Z202054).

\section{Data availability statement}

All data generated or analyzed during this study are included in this published article.

\section{Statement of Ethics}

The study was approved by the Human Research Ethics Committees of the First People's Hospital of Neijiang, Sichuan 641000 , China

\section{Consent for publication}

Not applicable.

\section{Competing interests}

The authors declare that they have no competing interests. 
Department of Neonatology, The First People's Hospital of Neijiang, Sichuan 641000, China

\section{References}

1. DiBlasi RM. Neonatal noninvasive ventilation techniques: do we really need to intubate? Respiratory care2011 Sep;56(9):1273-94; discussion 95-7.

2. Finer NN, Carlo WA, Walsh MC, Rich W, Gantz MG, Laptook AR et al. Early CPAP versus surfactant in extremely preterm infants. The New England journal of medicine2010 May 27;362(21):1970-9.

3. Scholze A, Lamwers S, Tepel M, Sanner BM. Nasal continuous positive airway pressure: influence on digital volume pulse in obstructive sleep apnoea patients. The European respiratory journal2012 May;39(5):1127-35.

4. Chao KY, Chen YL, Tsai LY, Chien YH, Mu SC. The Role of Heated Humidified High-flow Nasal Cannula as Noninvasive Respiratory Support in Neonates. Pediatrics and neonatology2017 Aug;58(4):295-302.

5. Heath Jeffery RC, Broom M, Shadbolt B, Todd DA. Increased use of heated humidified high flow nasal cannula is associated with longer oxygen requirements. Journal of paediatrics and child health2017 Dec;53(12):1215-19.

6. Armanian AM, Iranpour R, Parvaneh M, Salehimehr N, Feizi A, Hajirezaei M. Heated Humidified High Flow Nasal Cannula (HHHFNC) is not an effective method for initial treatment of Respiratory Distress Syndrome (RDS) versus nasal intermittent mandatory ventilation (NIMV) and nasal continuous positive airway pressure (NCPAP). Journal of research in medical sciences : the official journal of Isfahan University of Medical Sciences2019;24:73.

7. Manley BJ, Arnolda GRB, Wright IMR, Owen LS, Foster JP, Huang L et al. Nasal High-Flow Therapy for Newborn Infants in Special Care Nurseries. The New England journal of medicine2019 May 23;380(21):2031-40.

8. Soonsawad S, Swatesutipun B, Limrungsikul A, Nuntnarumit P. Heated Humidified High-Flow Nasal Cannula for Prevention of Extubation Failure in Preterm Infants. Indian journal of pediatrics2017 Apr;84(4):262-66.

9. Collins CL, Barfield C, Horne RS, Davis PG. A comparison of nasal trauma in preterm infants extubated to either heated humidified high-flow nasal cannulae or nasal continuous positive airway pressure. European journal of pediatrics2014 Feb;173(2):181-6.

10. Yoder BA, Stoddard RA, Li M, King J, Dirnberger DR, Abbasi S. Heated, humidified high-flow nasal cannula versus nasal CPAP for respiratory support in neonates. Pediatrics2013 May;131(5):e1482-90.

11. Manley BJ, Owen LS, Doyle LW, Andersen CC, Cartwright DW, Pritchard MA et al. High-flow nasal cannulae in very preterm infants after extubation. The New England journal of medicine2013 Oct 10;369(15):1425-33.

12. Kadivar MM, Mosayebi ZM, Razi NM, Nariman SM, Sangsari RM. High Flow Nasal Cannulae versus Nasal Continuous Positive Airway Pressure in Neonates with Respiratory Distress Syndrome Managed with INSURE Method: A Randomized Clinical Trial. Iranian journal of medical sciences2016 Nov;41(6):494-500.

13. Jin B, Wu JB, Zhou B, Liu X, Ma XH. Clinical research of heated humidified high-flow nasal cannula for prevention of extubation failure in preterm infants with respiratory distress syndrome. Chin Pediatr Emerg Med2019;26(3):206-10.

14. Gao XY, Feng L, Qiu YF, Pan XN. Application of humidified high-flow nasal cannula in neonates with meconium aspiration syndrome and pulmonary hypertension after extubation. Chin J Contrmp Pediatr2017;19(4):393-97.

15. Kang WQ, Xu BL, Liu DP, Zhang YD, Guo J, Li CH et al. Efficacy of heated humidified high-flow nasal cannula in preterm infants aged less than 32 weeks after ventilator weaning. Chin J Contrmp Pediatr2016;18(6):488-91.

16. Chen J, Xu F, Zhang T, Du LL, Gao WW. Comparison of heated humidified high flow nasal cannula and nasal continuous positive airway pressure for prevention of extubation failure in extremely low birth weight infants. Chinese Journal of Neonatology2016;31(2):86-90.

17. Liu C. Efficacy and safety of heated humidified high.flow nasal cannula for prevention of extubation failure in neonates. Chin J Pediatr2014;52(4):271-76. 
18. Li K, Wang YL, Ye XZ, Zhang Y, Chen YB. Application of humidified high flow nasal cannula for post-extubation support in preterm infants. Chinese Journal of Neonatology2014;29(5):306-09.

19. Volsko TA, Fedor K, Amadei J, Chatburn RL. High flow through a nasal cannula and CPAP effect in a simulated infant model. Respiratory care2011 Dec;56(12):1893-900.

20. de Klerk A. Humidified high-flow nasal cannula: is it the new and improved CPAP? Advances in neonatal care: official journal of the National Association of Neonatal Nurses2008 Apr;8(2):98-106.

21. Konda KC, Lewis LE, Bhat YR, Purkayastha J, Kanaparthi S. Heated Humidified High-Flow Nasal Cannula Versus Nasal Continuous Positive Airway Pressure for the Facilitation of Extubation in Preterm Neonates with Respiratory Distress. Iranian Journal of Neonatology2018 Jun;9(2):14-20.

22. Jeon GW. Respiratory support with heated humidified high flow nasal cannula in preterm infants. Korean journal of pediatrics2016 Oct;59(10):389-94.

23. Walsh BK, Brooks TM, Grenier BM. Oxygen therapy in the neonatal care environment. Respiratory care2009 Sep;54(9):1193-202.

24. Garg BD, Bajaj N, Sharma D. To Compare the Efficacy of Heated Humidified High-Flow Nasal Cannula and Continuous Positive Airway Pressure in Post-Extubation Period in VLBW Infants. Journal of tropical pediatrics2018 Aug 1;64(4):26266.

\section{Tables}

TABLE 1 The main characteristics of the eligible literatures included in the meta-analysis

\begin{tabular}{|c|c|c|c|c|c|c|c|}
\hline \multirow[t]{2}{*}{ ountry } & \multirow[b]{2}{*}{ NO } & \multicolumn{3}{|c|}{ HHHFNC } & \multicolumn{2}{|c|}{ NCPAP } & \multirow[t]{2}{*}{ outcomes } \\
\hline & & GA(weeks) ${ }^{1}$ & Birth weight $(\mathrm{g})$ & NO & GA(weeks) & Birth weight(g) & \\
\hline Shina & 128 & $35.4 \pm 3.5$ & $1550 \pm 482$ & 127 & $35.6 \pm 3.5$ & $1464 \pm 417$ & acdef \\
\hline tustralia & 67 & $27.9 \pm 1.95$ & $1123 \pm 317$ & 65 & $27.6 \pm 1.97$ & $1105 \pm 374$ & abcefghj \\
\hline tmerica & 212 & $33.5 \pm 3.6$ & $2201 \pm 816$ & 220 & $33.2 \pm 3.2$ & $2108 \pm 782$ & abceh \\
\hline tustralia & 152 & $27.7 \pm 2.1$ & $1041 \pm 338$ & 151 & $27.5 \pm 1.9$ & $1044 \pm 327$ & abcdeghi \\
\hline tustralia & 381 & $36.9 \pm 2.8$ & $2936 \pm 786$ & 373 & $36.9 \pm 3.0$ & $2885 \pm 790$ & abcde \\
\hline $\operatorname{ran}$ & 27 & $28 \square 34$ & No mention & 27 & $28 \square 34$ & No mention & abgi \\
\hline Jhina & 38 & $30.7 \pm 1.9$ & $1301 \pm 302$ & 37 & $30.4 \pm 1.9$ & $1265 \pm 298$ & adefghij \\
\hline Jhina & 79 & $26 \square 31$ & $1350 \pm 200$ & 82 & $26 \square 31$ & $1400 \pm 300$ & abcefgh \\
\hline Jhina & 28 & $32.6 \pm 1.5$ & $1269 \pm 165$ & 31 & $32.8 \pm 1.7$ & $1273 \pm 157$ & bcdefghij \\
\hline Zhina & 66 & $30.2 \pm 3.7$ & $861 \pm 124$ & 63 & $30.5 \pm 3.3$ & $878 \pm 136$ & abdefhi \\
\hline Zhina & 40 & $39.9 \pm 1.3$ & $3397 \pm 496$ & 38 & $39.4 \pm 1.5$ & $3375 \pm 434$ & adegj \\
\hline Thailand & 24 & $27.6(26,30)^{\mathrm{K}}$ & $900(800,1333)^{\mathrm{k}}$ & 25 & $28(25,29.5)^{\mathrm{k}}$ & $980(740,1237)^{\mathrm{K}}$ & abdfgh \\
\hline ran & 35 & $30.7 \pm 1.8$ & $1282 \pm 184$ & 37 & $29.9 \pm 3$ & $1153 \pm 226$ & abcg \\
\hline
\end{tabular}

a.Treatment failure rate; b. reintubation rate; c. mortality; d. nasal trauma; e. frequent hemorrhoid; f. BPD; g. IVH; h. NEC; i. ROP; j. duration of reaching full enteral feeding; $\mathrm{k} . \mathrm{M}\left(\mathrm{P}_{25} \square \mathrm{P}_{75}\right) ; \mathrm{l}$. GA: Gestational Age

TABLE 2 The pooled outcome of complications

\begin{tabular}{ccccccccc}
\hline No. of trials & \multicolumn{1}{c}{ HHHFNC } & \multicolumn{2}{c}{ NCPAP } & $\mathrm{I}^{2}$ & Effect-Model & outcomes & $\mathrm{P}$ \\
& case & total & case & total & & & & \\
\hline 7 & 93 & 430 & 103 & 430 & $0 \%$ & Fixed & $0.83[0.71,1.12]$ & 0.32 \\
8 & 19 & 662 & 29 & 675 & $0 \%$ & Fixed & $0.67[0.38,1.17]$ & 0.16 \\
8 & 32 & 666 & 50 & 674 & $7 \%$ & Fixed & $0.65[0.43,0.98]$ & 0.04 \\
5 & 58 & 311 & 53 & 309 & $0 \%$ & Fixed & $1.07[0.80,1.44]$ & 0.64 \\
\hline
\end{tabular}




\section{Figures}

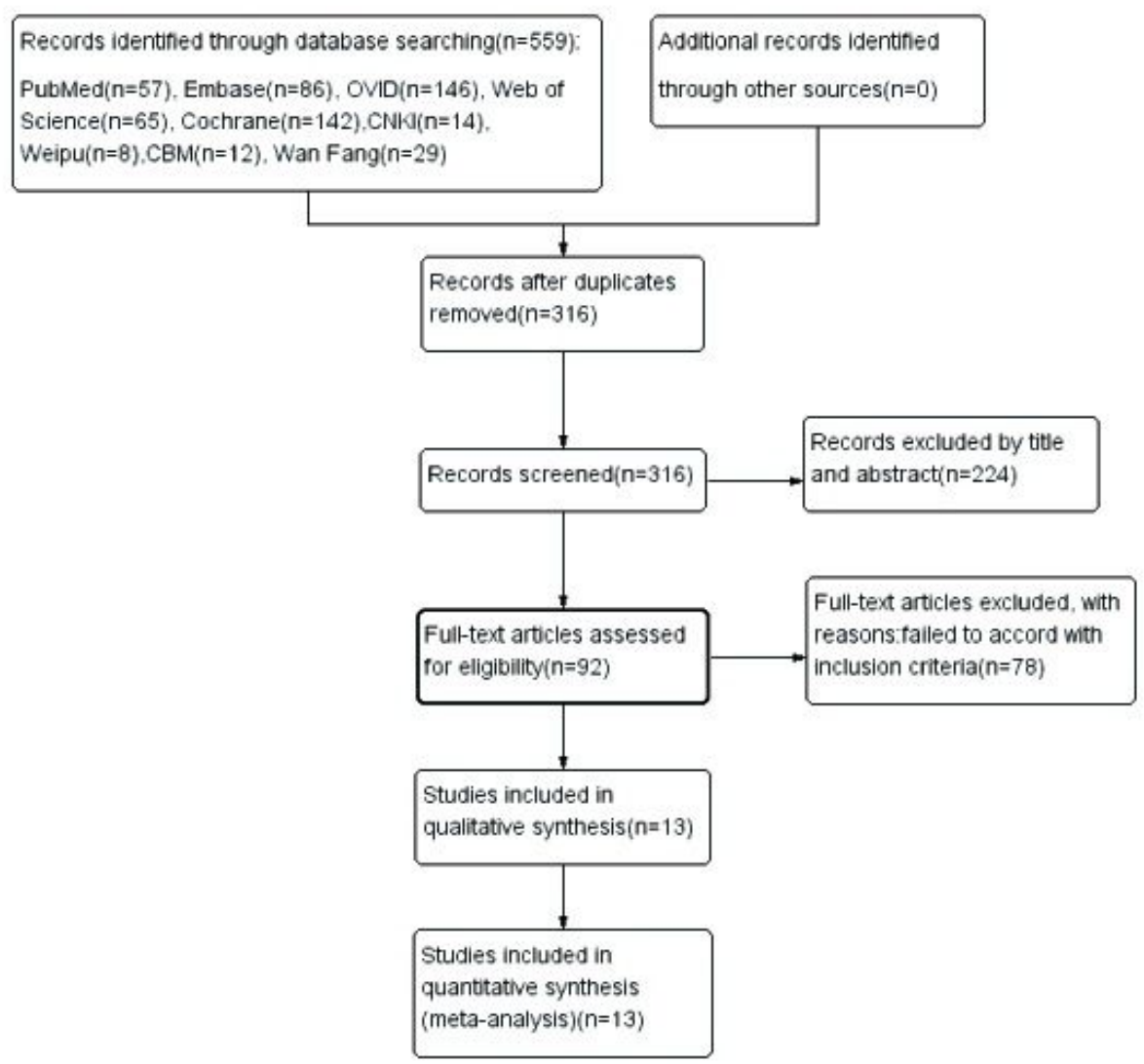

\section{Figure 1}

The flow diagram of the literatures selection procedure in this meta-analysis 


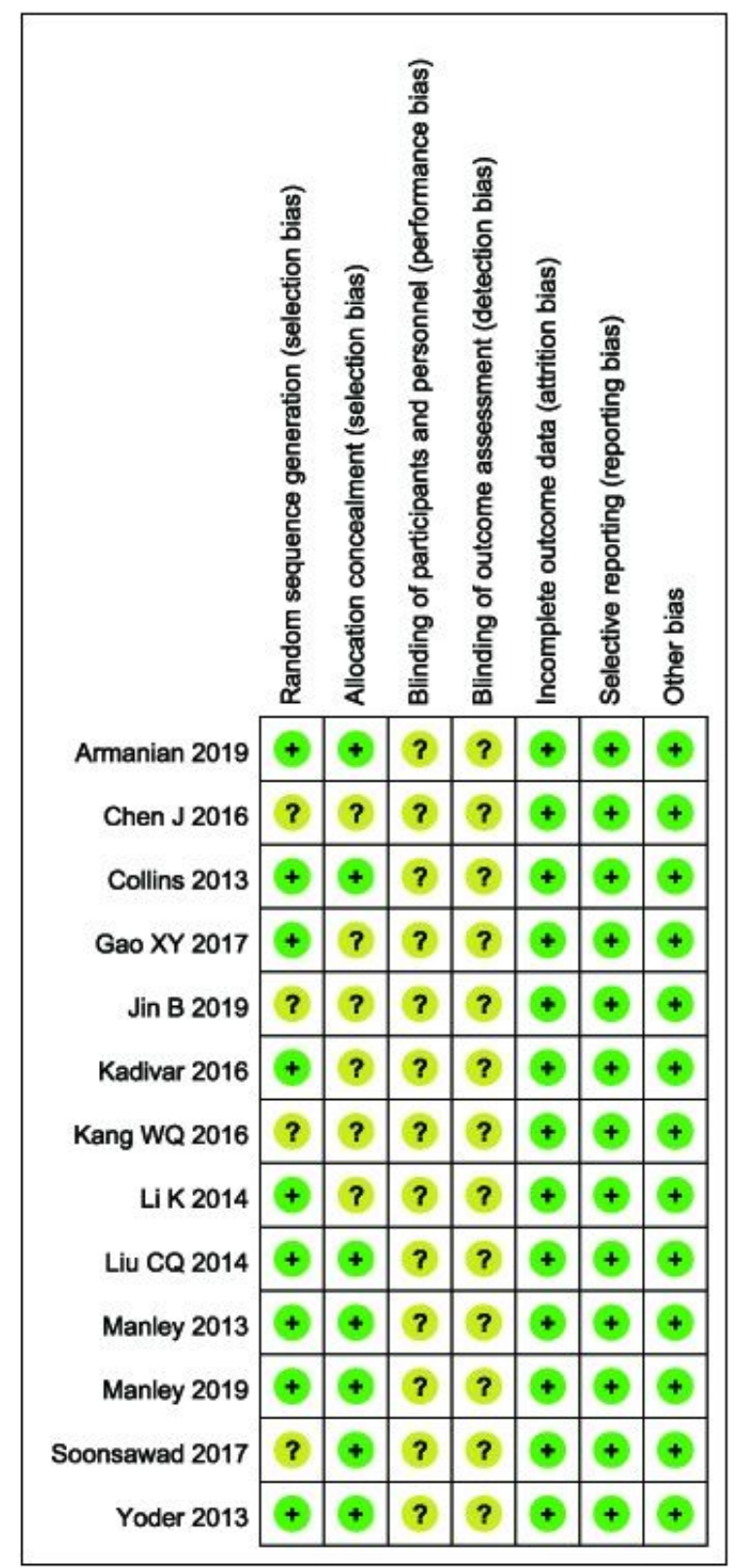

Figure 2

Risk of bias assessment summary of this meta-analysis

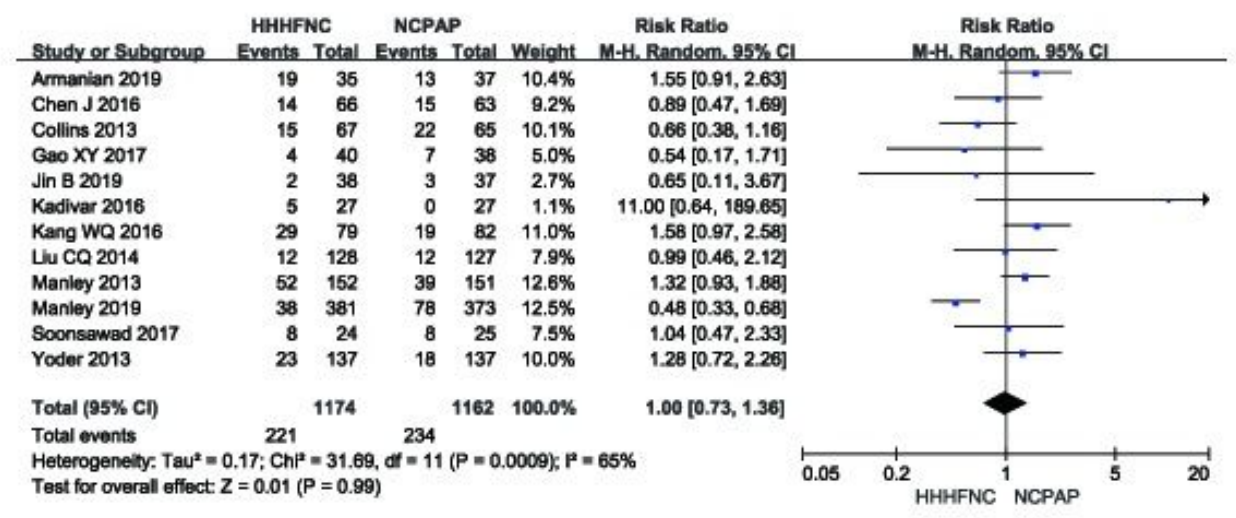




\section{Figure 3}

Forest of plot of the treatment failure rate between HHHFNC group and NCPAP group

\begin{tabular}{|c|c|c|c|c|c|c|c|c|c|c|}
\hline Study or Subgrous & $\begin{array}{l}\text { HHHFN } \\
\text { Events }\end{array}$ & $\begin{array}{l}\text { NC } \\
\text { Total }\end{array}$ & $\begin{array}{l}\text { NCPA } \\
\text { Events }\end{array}$ & Total & Weight & $\begin{array}{c}\text { Risk Ratio } \\
\text { M-H. Fluxed. } 95 \% \mathrm{cl}\end{array}$ & & $\begin{array}{r}\text { Risk F } \\
\text { M-th. Flxe }\end{array}$ & $\begin{array}{l}\text { Ratio } \\
\text { ed. } 95 \% \mathrm{Cl}\end{array}$ & \\
\hline Armanian 2019 & 5 & 35 & 12 & 37 & $7.3 \%$ & $0.44[0.17,1.12]$ & & & & \\
\hline Chen J 2016 & 17 & 66 & 30 & 63 & $19.3 \%$ & $0.54[0.33,0.88]$ & & & & \\
\hline Collins 2013 & 14 & 67 & 16 & 65 & $10.2 \%$ & $0.85[0.45,1.60]$ & & & & \\
\hline Kadlvar 2016 & 14 & 27 & 4 & 27 & $2.5 \%$ & $3.50[1.32,9.28]$ & & & & \\
\hline Kang WQ 2016 & 11 & 79 & 10 & 82 & $6.2 \%$ & $1.14[0.51,2.54]$ & & & & \\
\hline LI K 2014 & 3 & 28 & 4 & 31 & $2.4 \%$ & $0.83[0.20,3.39]$ & & & & \\
\hline Manley 2013 & 27 & 152 & 38 & 151 & $24.0 \%$ & $0.71[0.46,1.09]$ & & & & \\
\hline Manley 2019 & 21 & 381 & 22 & 373 & $14.0 \%$ & $0.93[0.52,1.67]$ & & & & \\
\hline Soonsawad 2017 & 2 & 24 & 2 & 25 & $1.2 \%$ & $1.04[0.16,6.81]$ & & & & \\
\hline Yoder 2013 & 23 & 212 & 21 & 220 & $13.0 \%$ & $1.14[0.65,1.99]$ & & & & \\
\hline Total $(95 \% \mathrm{CI})$ & & 1071 & & 1074 & $100.0 \%$ & $0.86[0.70,1.06]$ & & & & \\
\hline Total events & 137 & & 159 & & & & & & & \\
\hline $\begin{array}{l}\text { Helerogeneily: } \mathrm{Ch} \mathrm{i}^{2} \text { = } \\
\text { Test for overall effect. }\end{array}$ & $\begin{array}{l}79, \text { df }= \\
=1.42(P\end{array}$ & $\theta(P$ & $0.07) ; p=$ & $=43 \%$ & & & $0.1 \quad 0.2$ & $\underset{\text { HHHFNC }}{0.5} 1$ & $1 \underset{\text { NCPAP }}{2}$ & 5 \\
\hline
\end{tabular}

\section{Figure 4}

Forest of plot of the reintubation rate between HHHFNC group and NCPAP group

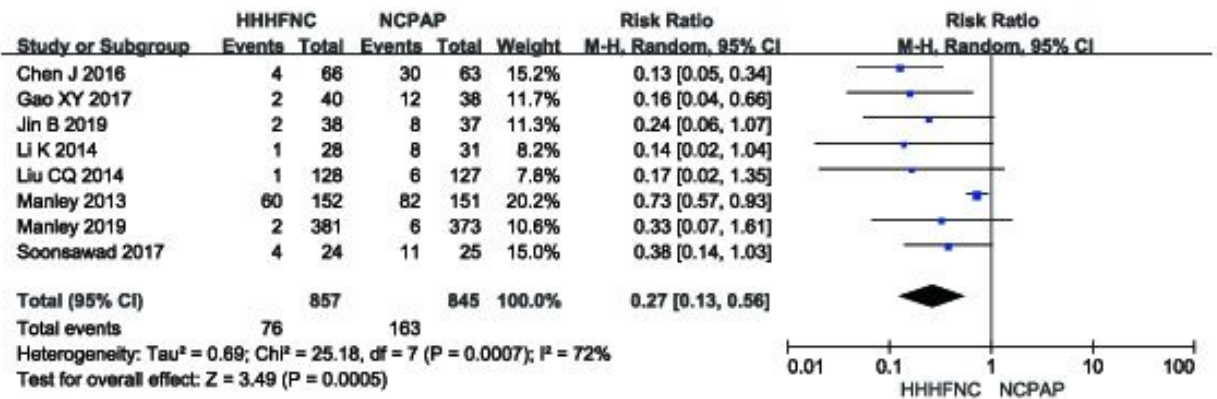

Figure 5

Forest of plot of the Incidence Rates of Nasal Trauma between HHHFNC group and NCPAP group

\begin{tabular}{|c|c|c|c|c|c|c|c|c|c|c|}
\hline Study or Subgrous & $\begin{array}{l}\text { HHHFN } \\
\text { Events }\end{array}$ & $\begin{array}{l}\text { NC } \\
\text { Total }\end{array}$ & $\begin{array}{l}\text { NCPA } \\
\text { Events }\end{array}$ & Total & Weight & $\begin{array}{l}\text { Risk Ratio } \\
\text { M-H.Fluxed. } 95 \% \text { CI }\end{array}$ & & $\begin{array}{r}\text { Risk F } \\
M=\text { H. Flxe: }\end{array}$ & $\begin{array}{l}\text { Ratio } \\
\text { od. } 95 \% \mathrm{Cl}\end{array}$ & \\
\hline Chen J 2016 & 0 & 0 & 0 & 0 & & Not estimable & & & & \\
\hline Collins 2013 & 0 & 67 & 1 & 65 & $3.6 \%$ & $0.32[0.01,7.80]$ & & & & \\
\hline Gao XY 2017 & 0 & 40 & 2 & 38 & $6.1 \%$ & $0.19[0.01,3.84]$ & & & & \\
\hline $\operatorname{Jin} B 2019$ & 3 & 38 & 3 & 37 & $7.2 \%$ & $0.97[0.21,4.52]$ & & & & \\
\hline Kang WQ 2016 & 0 & 79 & 1 & 82 & $3.5 \%$ & $0.35[0.01,8.36]$ & & & & \\
\hline LI K 2014 & 0 & 28 & 1 & 31 & $3.4 \%$ & $0.37[0.02,8.68]$ & & & & \\
\hline Liu CQ 2014 & 1 & 128 & 4 & 127 & $9.5 \%$ & $0.25[0.03,2.19]$ & & & & \\
\hline Manley 2013 & 1 & 152 & 5 & 151 & $11.9 \%$ & $0.20[0.02,1.68]$ & & & & \\
\hline Manley 2019 & 9 & 381 & 18 & 373 & $43.2 \%$ & $0.49[0.22,1.08]$ & & & & \\
\hline Yoder 2013 & 1 & 212 & 5 & 220 & $11.6 \%$ & $0.21[0.02,1.76]$ & & & & \\
\hline Total $(95 \% \mathrm{Cl})$ & & 1125 & & 1124 & $100.0 \%$ & $0.40[0.23,0.70]$ & & & & \\
\hline Total events & 15 & & 40 & & & & & & & \\
\hline \multicolumn{7}{|c|}{$\begin{array}{l}\text { Helerogeneity: Chiz }=2.76, \text { df }=8(P=0.96) ; P=0 \% \\
\text { Test for overall effect: } Z=3.22(P=0.001)\end{array}$} & 0.01 & ${ }_{\text {HHHFNC }}^{0.1}$ & $1_{\text {NCPAP }}$ & 10 \\
\hline
\end{tabular}

Figure 6 


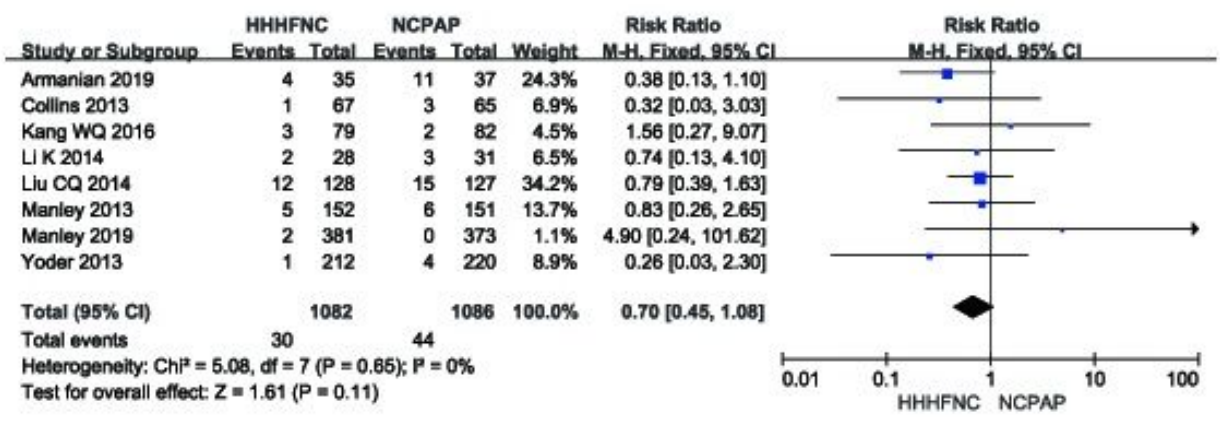

\section{Figure 7}

Forest of plot of hospital mortality between HHHFNC group and NCPAP group

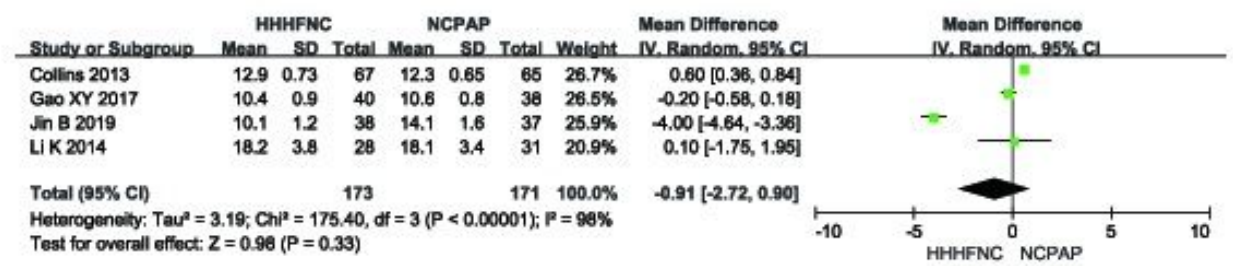

\section{Figure 8}

Forest of plot of the duration of reaching full enteral feedings between HHHFNC group and NCPAP group

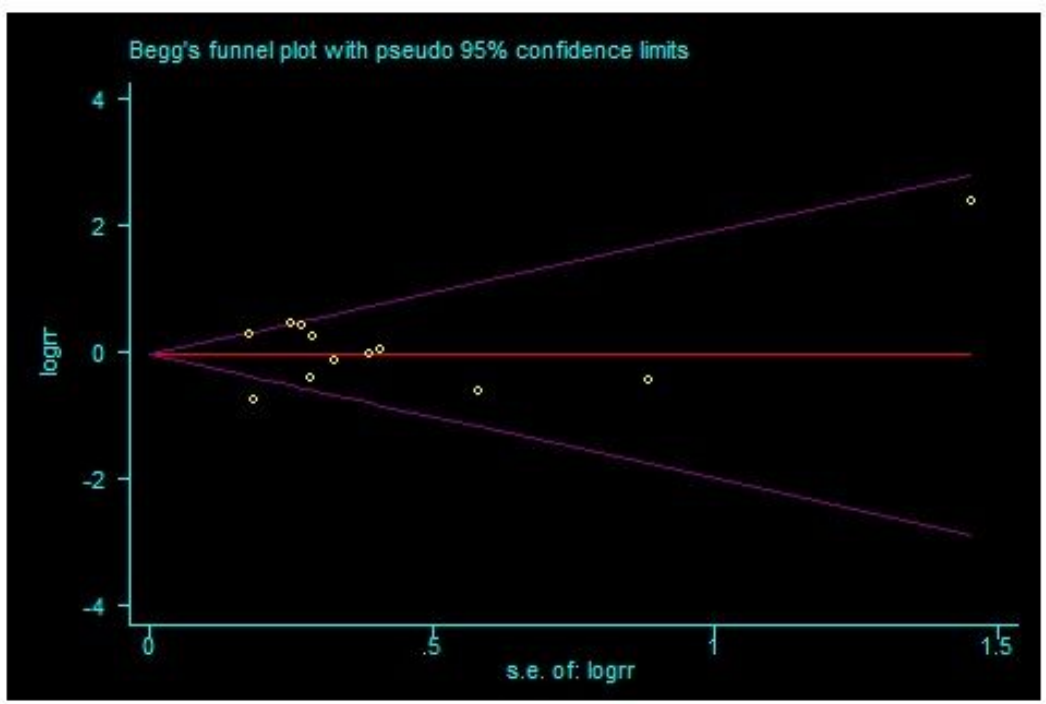

\section{Figure 9}

Begg's test funnel plot of the Treatment Failure Rate 


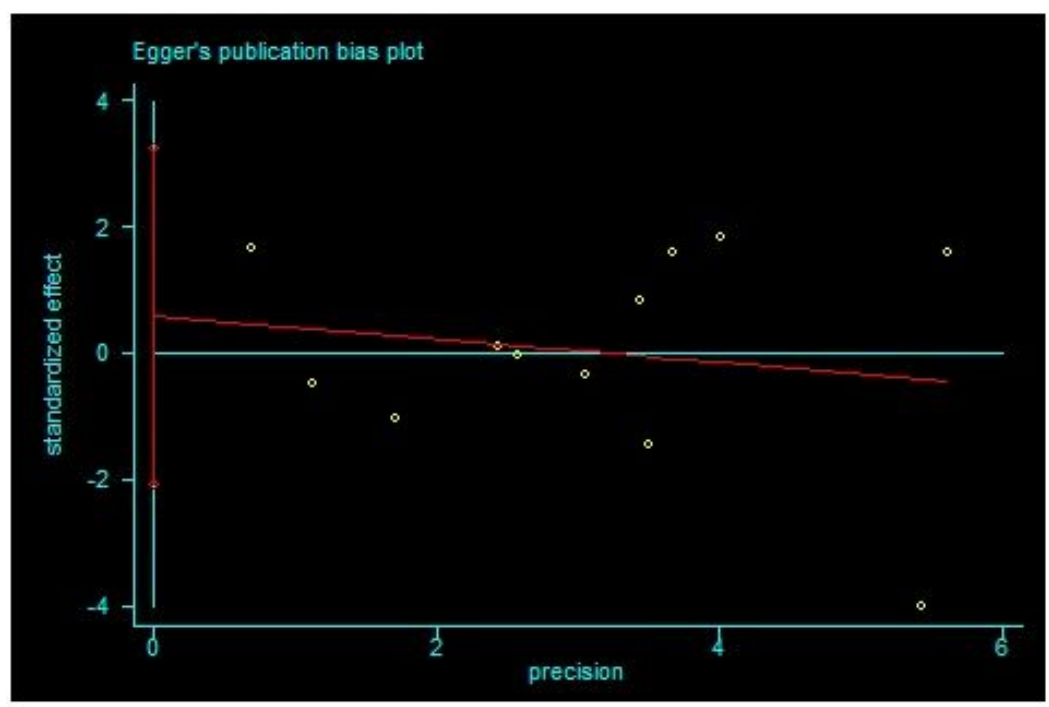

Figure 10

Egger's test funnel plot of the Treatment Failure Rate 